\title{
Low-Frequency Noise and Microplasma Analysis for c-Si Solar Cell Characterization
}

\author{
Jiří Vanek, ${ }^{1}$ Jan Dolensky, ${ }^{1}$ Zdenek Chobola, ${ }^{2}$ Mirek Luňák, ${ }^{2}$ and Aleš Poruba ${ }^{3}$ \\ ${ }^{1}$ Department of Electrotechnology, Faculty of Electrical Engineering and Communication, Brno University of Technology, Udolni 53, \\ 60200 Brno, Czech Republic \\ ${ }^{2}$ Department of Physics, Faculty of Civil Engineering, Brno University of Technology, Žižkova 17, 60200 Brno, Czech Republic \\ ${ }^{3}$ Department of Solar-Cells, Solartec s.r.o., Televizní 2618, 76561 Rožnov pod Radhoštěm, Czech Republic
}

Correspondence should be addressed to Zdenek Chobola, chobola@dp.fce.vutbr.cz

Received 2 September 2011; Accepted 5 December 2011

Academic Editor: Stephen Bremner

Copyright (C) 2012 Jiří Vanek et al. This is an open access article distributed under the Creative Commons Attribution License, which permits unrestricted use, distribution, and reproduction in any medium, provided the original work is properly cited.

This paper brings the comparison of solar cell conversion efficiency and results from a noise spectroscopy and microplasma presence to evaluate the solar cell technology. Three sets of monocrystalline silicon solar cells (c-Si) varying in front side phosphorus doped emitters were produced by standard screen-printing technique. From the measurements it follows that the noise spectral density related to defects is of $1 / f$ type and its magnitude. It has been established that samples showing low noise feature high-conversion efficiency. The best results were reached for a group solar cells with selective emitter structure prepared by double-phosphorus diffusion process.

\section{Introduction}

It is generally accepted that there are some fundamental sources of noise which generate the noise background. This is the case of the thermal noise, shot, noise and, as was shown recently, of the fundamental quantum $1 / f$ noise [1]. Besides the fundamental noise, which cannot be eliminated from any device, there exists excess noise which is believed to carry information on the device technology and structure defects which are either nonintentionally introduced during the device production or appear as results of the degradation processes during the device operation.

As it is well known, the noise spectral density increases with stress and damage and varies among nominally identical devices. Therefore, the excess noise is not of fundamental origin.

It is common experience that there are "good quality" and "poor quality" specimens. The noise level can vary considerably among nominally identical devices made by the same techniques and even at the same times. The sensitivity of the noise magnitude is typical feature of many samples and is caused by the effect of structure defects and other irregularities. Since the effect is due to a variable which is not controlled, the identification of the actual source is not easy. Very detailed experiments with many variables are needed to give a positive identification.

General conclusions are more common and state that noise depends on

(i) imperfections of the crystal structure, number of grain boundaries, point defects, linear defects, and so forth;

(ii) surface parameters;

(iii) homogeneity of $\mathrm{PN}$ junction region

Energy changes of the state of electron in a semiconductor are not indicated by light emission only but are also displayed on resulting current characteristics in both time and voltage dependence. They can be quantitatively evaluated not only by their mean values, but also by other statistical characteristics such as the correlation function or spectral output density. Considering the reality that the defects in silicon crystal grid are sources of oversize noise resulting in degradation of physical and technical parameters, noise characteristics can be used to evaluate 


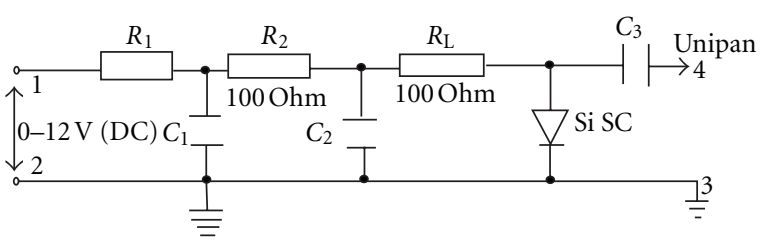

Figure 1: Circuit diagram of a solar cell sample.

the quality and service life of the observed system and its components classified.

As it was already shown in previous publications [1-3], noise spectral density reflects the quality of solar cells, and thus it represents an alternative advanced cell diagnostic tool. This paper deals with comparisons of noise spectroscopy [3] and detection of microplasma noise sources for three types of solar cells with screen-printed metallization varying in emitter structures.

\section{Experimental Procedure}

The first set of c-Si solar cells (here denoted as group 3149) was prepared with homogeneous emitter doped to the sheet resistance of about $52 \mathrm{Ohm} / \mathrm{sq}$. The second group of samples (3147) represents advanced cell structure concept with selective emitter structure prepared by single phosphorus diffusion where shallow doped regions were formed by using isishape SolarEtch CES etching paste from Merck company. In the third group 3150 the solar cells with selective emitters (SE) were prepared by double "deep" phosphorus diffusion process where the shallow emitters were prepared from deep diffused n+ layer by wet chemical "nanoetching."

Produced solar cells were first characterized by standard techniques such as an illuminated $I$ - $V$ curve measurement (sun simulator $1000 \mathrm{~W} / \mathrm{m}^{2}$, AM1.5), LBIC (650 nm), EQE, and Suns-Voc in Solartec. Then all the samples were transported to the advanced characterizations (noise diagnostics and microplasma detection) to the Brno University of Technology.

Figure 1 shows the electronic circuit used to measure the noise characteristic of solar cells samples. A DC voltage from a DC power supply is applied across points 1 and 2 . Resistances $R_{1}$ and $R_{2}$ and capacitors $C_{1}$ and $C_{2}$ are used to suppress spurious effects of the measuring equipment. The load resistance $R_{L}$ has been chosen to be $100 \Omega$. The noise voltage to be analyzed passes through a coupling capacitor $C_{3}$ between points 3 and 4 to be fed into the input of Unipan 233-7 low-noise preamplifier, subsequently processed and recorded.

Since the noise voltage across the load resistance is measurable quantity, the testing procedure is based on the load resistance noise voltage data collection. The highest resolution of the current noise spectral density is obtained for the current values corresponding to the power matching condition. The ratio of the total measured noise to the background noise has a maximum value at this point.

The voltage noise spectral density was measured in forward biased voltage $[4,5]$ being picked up across a load resistance $R_{L}=100 \Omega$ at a band mean frequency of $1 \mathrm{kHz}$ and a bandwidth of $20 \mathrm{~Hz}[6,7]$.

When reverse electric field is applied to a $\mathrm{PN}$ junction with some technological imperfections like local shunts, dislocation in PN junction or crystal-grid defects causing nonhomogeneity of parameters it produces enhanced impact ionization in tiny areas called microplasma $[8,9]$. It can lead onwards to deterioration in a cell quality or to destruction of PN junction. Energy changes of the state of electron in a semiconductor are not indicated by light emission only but are also displayed on resulting current characteristics in both time and voltage dependence. This is used by noise diagnostic methods based on the fact that owing to the microstructure of a substance material matter, and all processes taking place in the substance are stochastic and are manifested by fluctuations of macroscopically measurable quantities. They can be quantitatively evaluated not only by their mean values, but also by other statistical characteristics such as correlation function or spectral output density. It is going usually of generation-recombination noise in which dependence on frequency is of type $1 / f^{2}$. Microplasma is detectable well before the reverse breakdown of the PN junction.

Microplasma light emission is exhibited in a full spectrum range thus a CCD camera in a dark cryogenic box can be used. The apparatus for the method contains highly sensitive low-noise CCD camera G2-3200 with CCD chip by Kodak KAF-3200ME. It can be cooled down to $-20^{\circ} \mathrm{C}$. Camera contains set of optical filters, special objectives, and equipment for contacting solar cells. Solar cell is connected to reverse bias DC power source. Signal form CCD camera is analyzed by $\mathrm{PC}$ computer. The contact area is placed on dish with LN2. The temperature of underside area is $-21^{\circ} \mathrm{C}$. Due to the cooling it is possible to observe the smallest defects in solar cells. The number of the visible defects in solar cell depends on connected reversed biased voltage (RBV). During increasing reverse biased voltage, it is possible to observe more shining points. Standard exposure time is about $20 \mathrm{~s}$.

\section{Experimental Results}

Figure 2 illustrates the voltage noise spectral density versus applied DC voltage. The highest resolution of the noise spectral density is obtained for voltage values corresponding to the power-matching condition $\left(U_{F 1}=0.3 \mathrm{~V}\right)$. In a region at a voltage above $U_{F 2}=0.55 \mathrm{~V}$, we can see an accrual of excess noise component whose source comes from the contact series resistance $R_{\mathrm{S}}$. Progress of the noise voltage spectral density in this region characterizes the contact series resistance state.

Figure 3 shows a voltage noise spectral density $S_{U}$ versus frequency at a temperature $T=300 \mathrm{~K}$, the noise voltage being picked up from a load resistor $R_{L}=100 \Omega$ for the cells from the 3149 group. The curve labeled $U_{F}=0 \mathrm{~V}$ indicates the measuring setup background noise. The shapes of the noise curves for the applied DC forward voltage $U_{F}=0.3 \mathrm{~V}$ (various samples) show the excess noise component to be of the $1 / f^{1}$ type or $1 / f^{2}$ type which is typical of the generationrecombination (g-r) noise. 


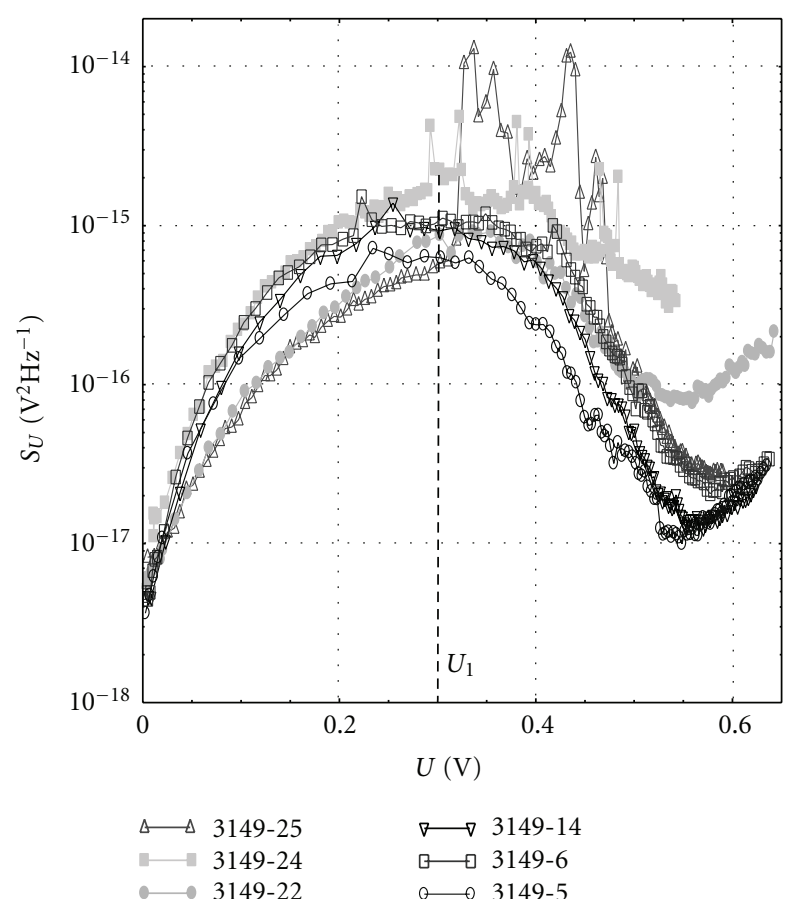

FIGURE 2: The noise spectral density as a function of forward voltage for group of samples 3149 .

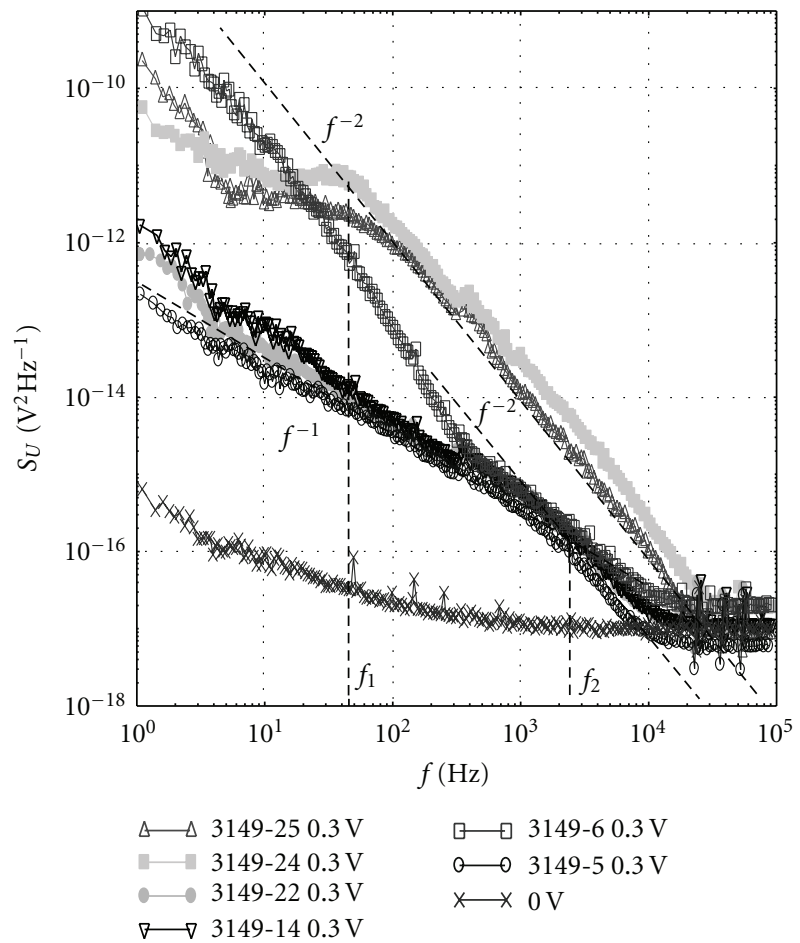

FIgURE 3: The noise spectral density versus frequency for group of samples 3149 .

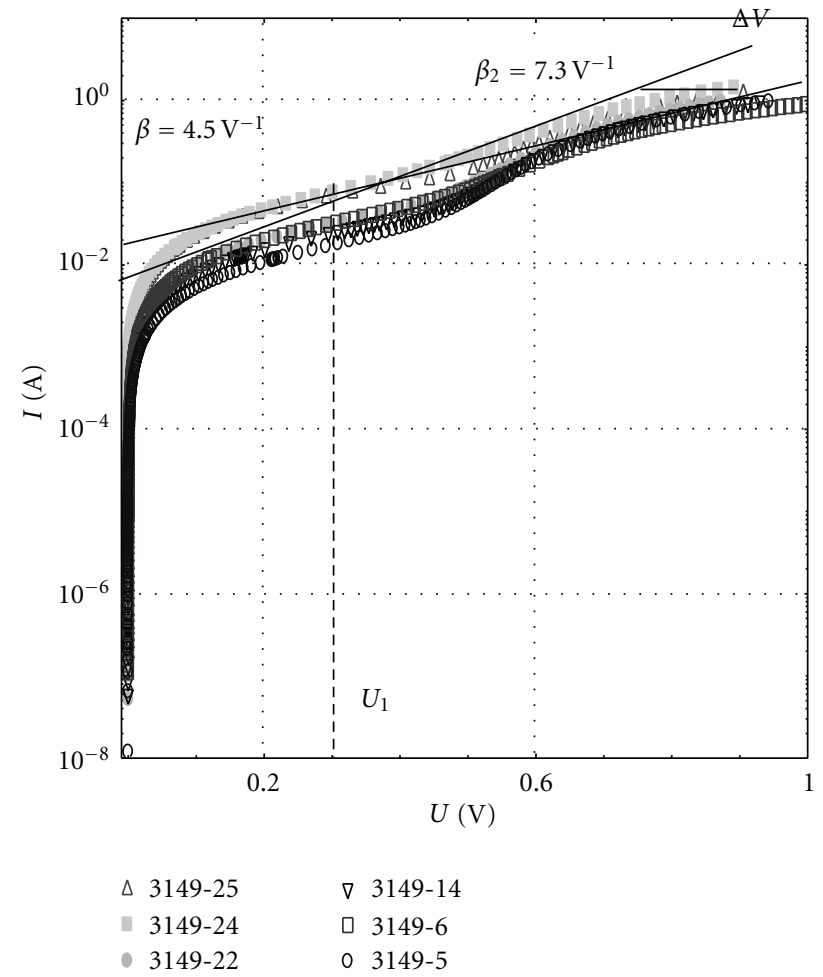

FIGURE 4: Dark $I-V$ characteristics of the group of solar cells 3149 (homogeneous emitters).

Excess noise parameters correlate very well with the transport characteristic measurement shown in Figure 4. In the area of $U_{F 1}=0.3 \mathrm{~V}$, we can for samples no. 24 and no. 25 observe significant component of excess current which is also reflected in the low value of exponent $\beta_{1}=4.5 \mathrm{~V}^{-1}$. The value of capacity at a voltage $U_{F 1}=0.3 \mathrm{~V}$ is about $620 \mathrm{nF}$ (surface area $100 \mathrm{~cm}^{2}$ ).

Figure 5 shows the dependence of noise spectral density on the applied DC voltage for the solar-cells from the 3150 group. Average value of $S_{U \text { MAX }}$ is the lowest of all three studied groups and reached only $S_{U \text { MAX }}=3 \cdot 10^{-16} \mathrm{~V}^{2} \mathrm{~Hz}^{-1}$.

In Figure 6 the correlation between spectral density $S_{U \text { MAX }}$ and solar cell efficiency is shown. We can see high correlation factor in all three groups of samples.

\section{Discussion}

The generation of microplasma is influenced by several factors. The first of them is defected silicon crystal-grid causing nonhomogeneity of parameters that, in turn, creates visible defect. The second is dislocation and impurities in PN junction. At places where junction is thinner or mechanically damaged, the microplasma discharge and emission of light is present.

Another sign of observed microplasma is noise, which has random spectrum in frequency range. Microplasma noise is measurable even before the creation of light emissions. That provides a way to obtain information about microplasma creation with exiguous reverse voltage. 


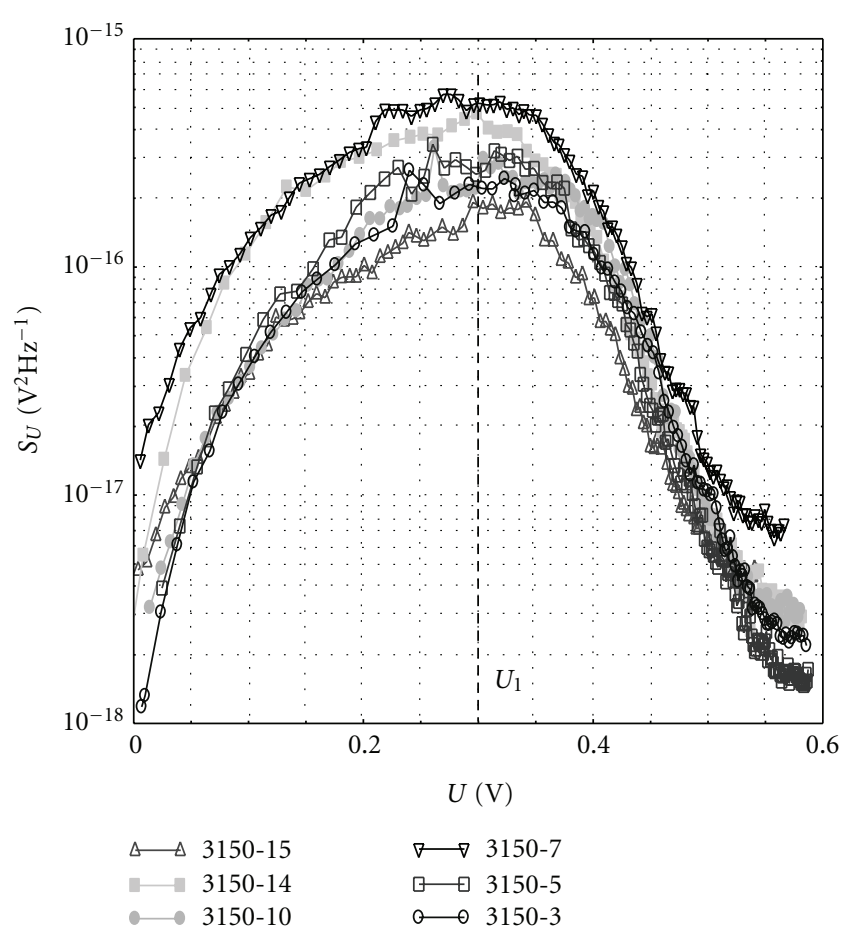

FIGURE 5: The noise spectral density as a function of forward voltage for group of samples 3150 .

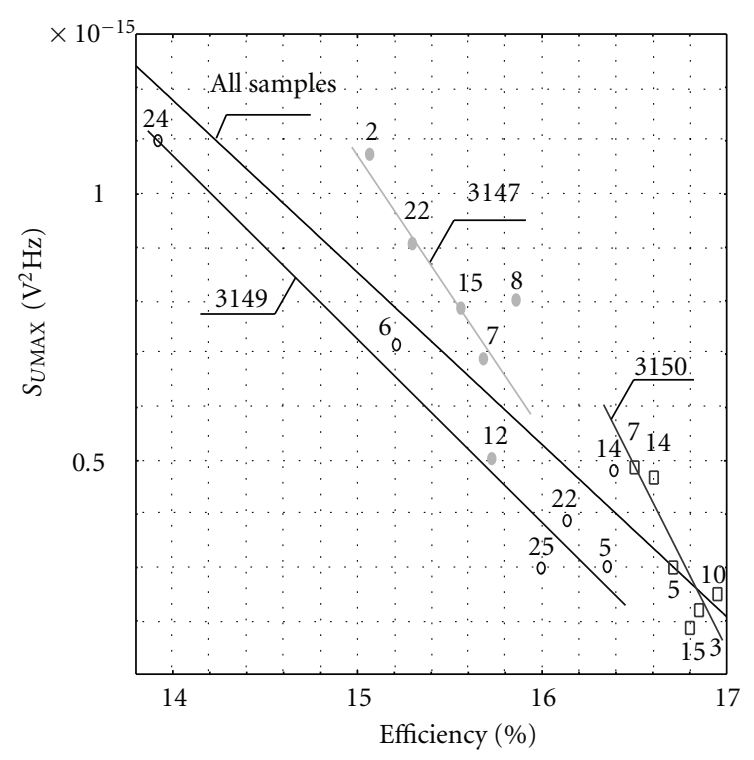

FIGURE 6: The correlation between spectral voltage density $S_{U \text { MAX }}$ and conversion efficiency of the solar cells from all groups.

The microplasma light intensity highly depends on reversed biased voltage. The results from noise diagnostic (see examples nos. 3149-25, 3149-24, and 3149-6) show strong correlation between type of technology (used texture) and noise level. The output from observed microplasma of each cell shows that the correlation between these two methods can exist. For a sample 3150-15, we have observed at a voltage of $4.0 \mathrm{~V}$ presence of about 30 microplasma sources

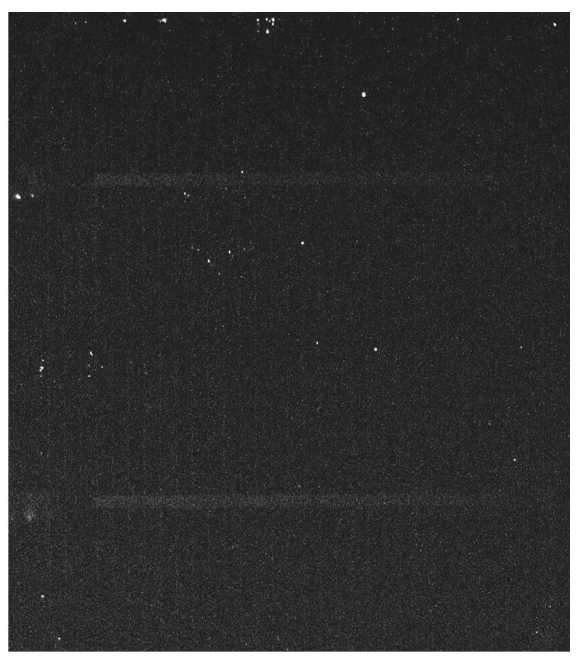

Figure 7: Microplasma method-scanning time $20 \mathrm{~s}$, voltage $4.0 \mathrm{~V}$, current $0.15 \mathrm{~A}$, sample no. 3150-15.

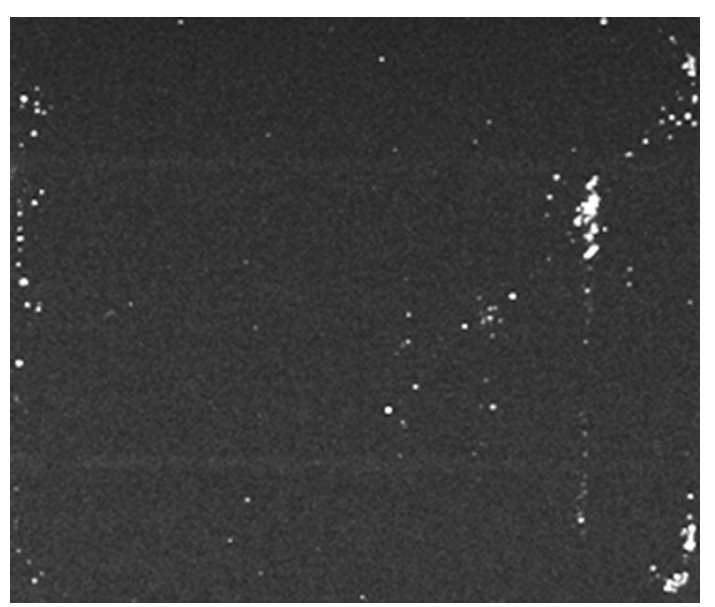

FIGURE 8: Microplasma method-scanning time $20 \mathrm{~s}$, reverse voltage $4.0 \mathrm{~V}$, current $0.15 \mathrm{~A}$, sample no. 3149-25.

(Figure 6), while, at the sample 3149-25, the number was about 200, this is approximately 6 times higher (Figure 7).

Figure 7 shows results of a microplasma-emitted light for the sample no. 3150-15. This sample generated very small noise voltage spectral density of (for only $S_{U M A X}=2$. $\left.10^{-16} \mathrm{~V}^{2} \mathrm{~Hz} U_{F 1}=0.3 \mathrm{~V}\right)$, and its efficiency was quite high of about $16.8 \%$.

The number of microplasma counts for sample No. 314925 is significantly greater and depends on connected reversed biased voltage (RBV) (Figures 8 and 9). The noise spectral density reaches value over $S_{U \text { MAX }}=1 \cdot 10^{-14} \mathrm{~V}^{2} \mathrm{~Hz}$ for voltage $0.3 \mathrm{~V}$.

\section{Conclusion}

The article compares the results from noise spectroscopy, microplasma presence, and solar-cell efficiency. From the measured results, it follows that the noise spectral density 


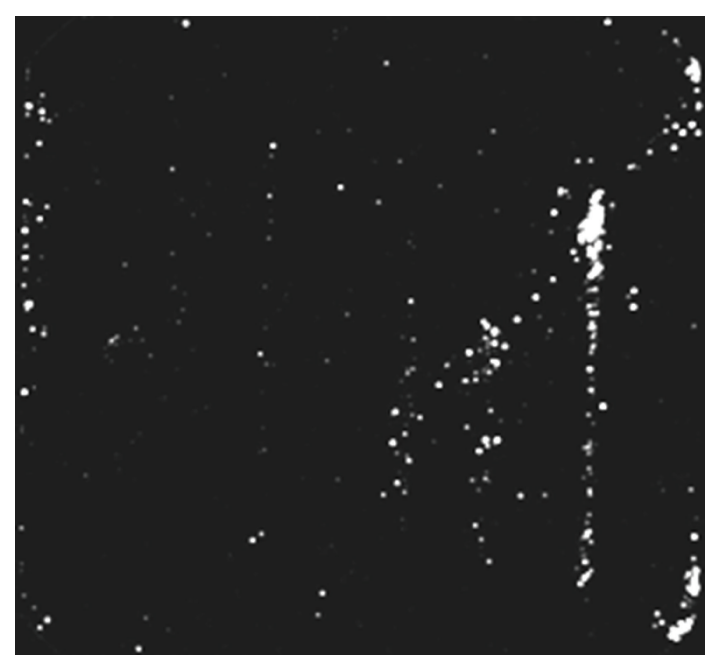

Figure 9: Microplasma method-scanning time $20 \mathrm{~s}$, reverse voltage 8.0 V, sample no. 3149-25.

related to defects is of $1 / f$ and generation-recombination types. Samples with lower noise voltage spectral density of only $S_{U \text { MAX }}=2 \cdot 10^{-16} \mathrm{~V}^{2} \mathrm{~Hz}$ for $U_{F 1}=0.3 \mathrm{~V}$ have smaller number of microplasma counts around 30 for voltage of $4.0 \mathrm{~V}$ and higher efficiency $16.5 \%-17.0 \%$. Samples with great noise voltage spectral density over $S_{U \text { MAX }}=6 \cdot 10^{-16} \mathrm{~V}^{2} \mathrm{~Hz}$ for $U_{F 1}=0.3 \mathrm{~V}$ have the number of microplasma counts greater than 200 for voltage $4.0 \mathrm{~V}$ and smaller efficiency $14.0 \%-16.0 \%$.

Data presented in Figure 6 shows not only good correlation of the spectral voltage density with conversion efficiency of all solar cells but one can identify small variation in the tangent of this relationship corresponding to the cells differing in emitter structure. This behavior will be subject of next intensive study.

\section{Acknowledgment}

This paper is based on the research supported by Grant Agency of the Czech Republic, Grant no. 102/09/0859, the Project FEKT-S-11-7, and by Ministry of Industry and Trade within the Project 2A-1TP1/075.

\section{References}

[1] L. K. J. Vandamme, R. Alabedra, and M. Zommiti, "1/f noise as a reliability estimation for solar cells," Solid State Electronics, vol. 26, no. 7, pp. 671-674, 1983.

[2] A. van der Ziel, "Low frequency noise suppression in space charge limited solid state diodes," Electronics, vol. 39, no. 24, pp. 95-97, 1966.

[3] T. G. Kleinpenning, "1/f noise in electronic devices," in Proceedings of the International Conference on Noise in Physical Systems, A. Ambrozy, Ed., pp. 443-454, Budapest, Hungary, 1989.

[4] J. Šikula, V. Sedláková, M. Tacano, and T. Zedníček, "Reliability of electronic devices: failure mechanisms and testing," in Reliability, Risk and Safety, pp. 1925-1936, Taylor \& Francis, London UK, 2009.
[5] Z. Chobola, "Noise as a tool for non-destructive testing of single-crystal silicon solar cells," Microelectronics Reliability, vol. 41, no. 12, pp. 1947-1952, 2001.

[6] L. K. J. Vandamme, "Opportunities and limitations to use lowfrequency noise as a diagnostic tool for device quality," in Proceedings of the 17th International Conference (ICNF'03), pp. 735-748, Prague, Czech Republic, 2003.

[7] Z. Chobola, "Impulse noise in silicon solar cells," Microelectronics Journal, vol. 32, no. 9, pp. 707-711, 2001.

[8] Z. Chobola, "Noise as a tool for non-destructive testing of single-crystal silicon solar cells," Microelectronics Reliability, vol. 41, no. 12, pp. 1947-1952, 2001.

[9] V. Jiri, K. Pavel, D. Jan, V. Ales, C. Zdenek, and P. Petr, "Microplasma luminescence and signal noise used to solar cells defects diagnostic," in the 20th International Conference on Noise and Fluctuations (ICNF '09), pp. 641-644, June 2009. 


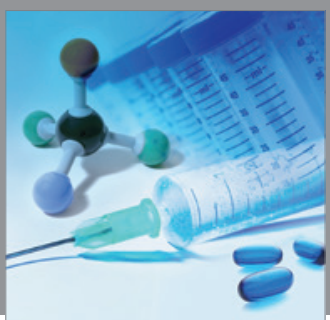

International Journal of

Medicinal Chemistry

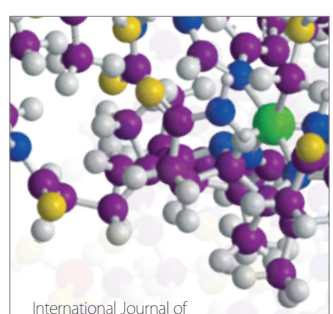

Carbohydrate Chemistry

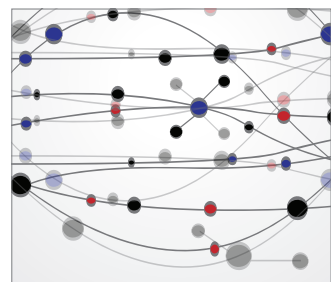

The Scientific World Journal
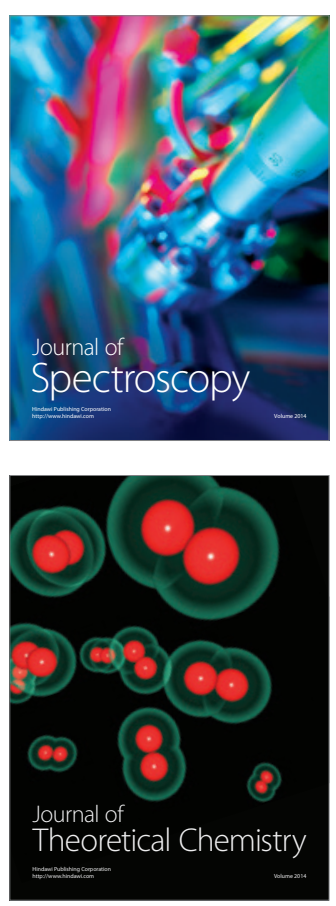
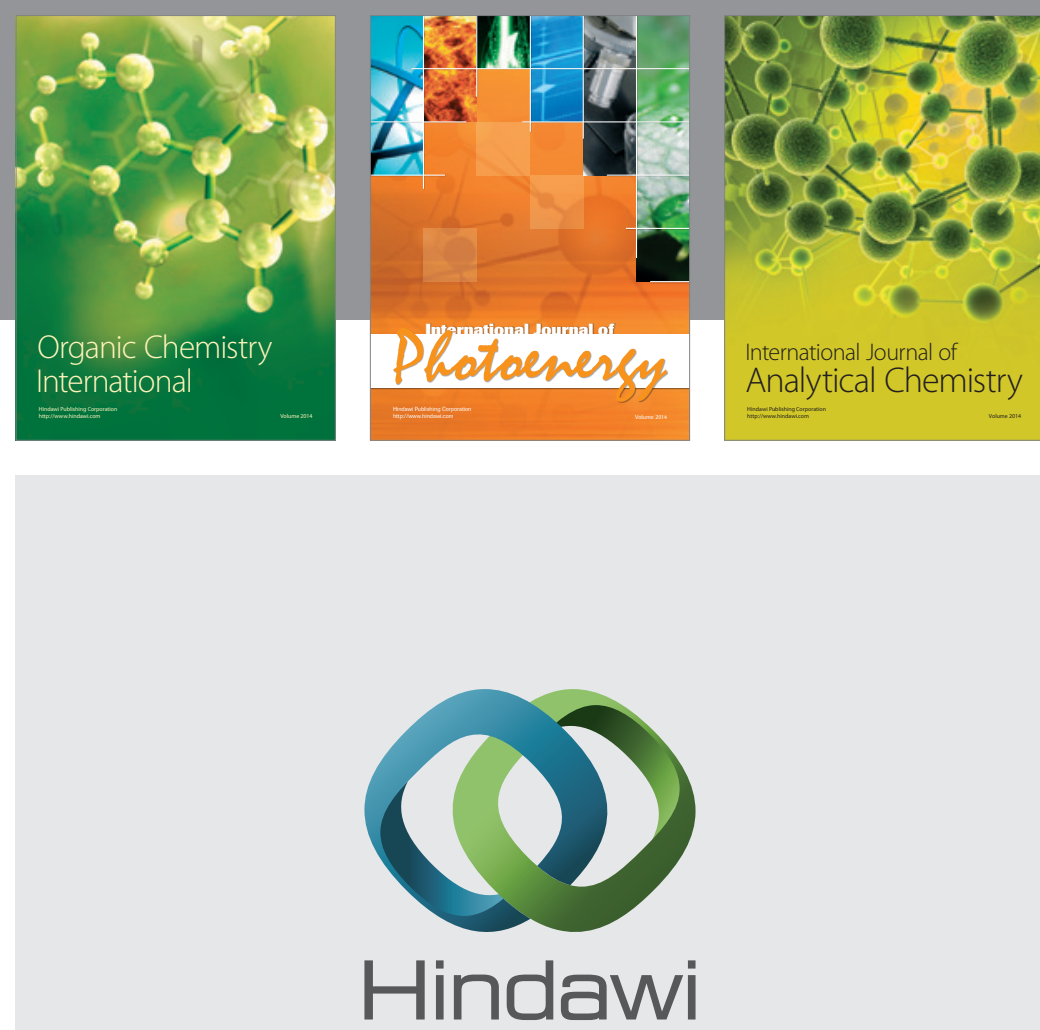

Submit your manuscripts at

http://www.hindawi.com
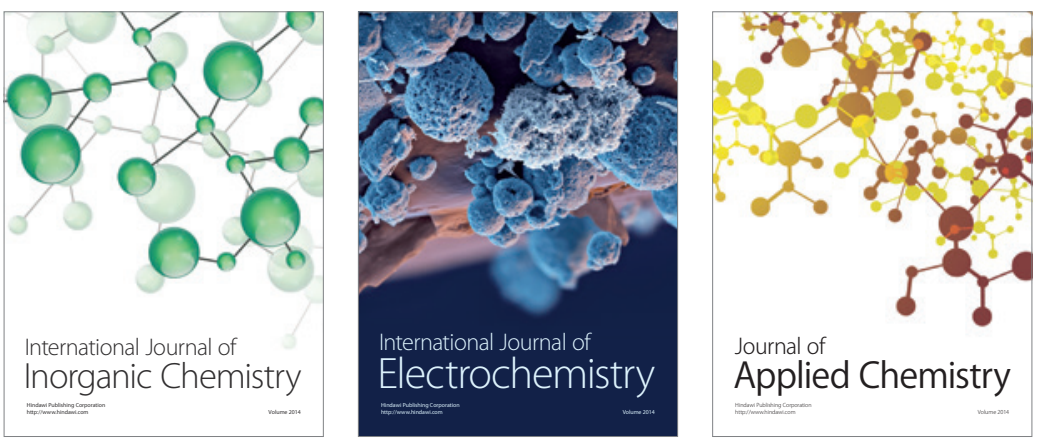

Journal of

Applied Chemistry
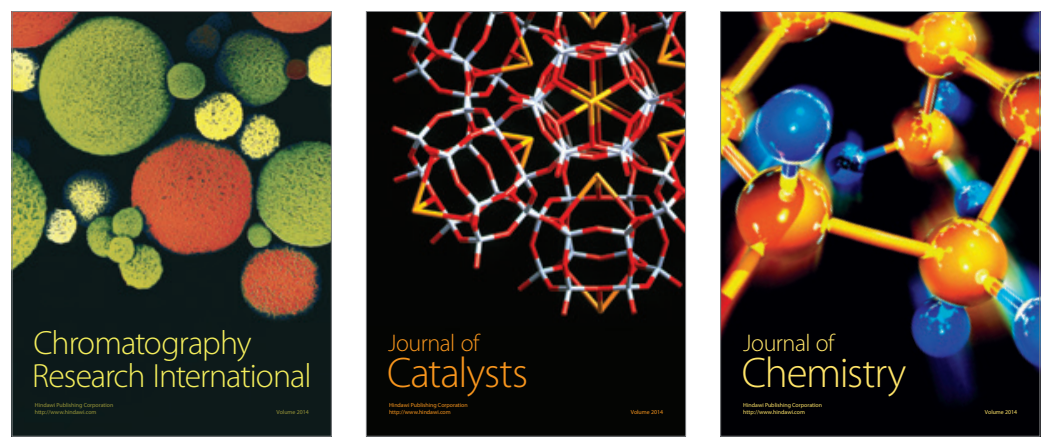
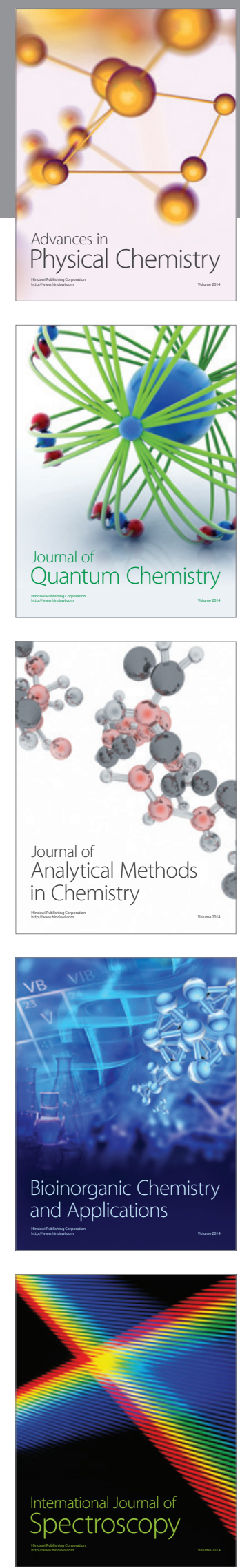